\title{
Report:
}

\section{Births in England and Wales, 2008}

\section{Introduction}

This update summarises some of the findings from the Office for National Statistics (ONS) annual reference volume Birth Statistics 2008 (series FM1 no. 37), published in December 2009 and other live births releases throughout the year. It presents data and analysis on recent trends in live births in England and Wales, and focuses on characteristics of births occurring in 2008. Particular attention is given to:

- number of births and Total Fertility Rate

- $\quad$ timing of childbearing

- family size

- births by marital status of mother

- multiple births

- $\quad$ fertility patterns within the United Kingdom

- births to mothers born outside the United Kingdom.

The annual reference volume with more detailed information on these, and other themes is available at: www.statistics.gov.uk/statbase/ Product.asp?vlnk=5768

\section{Number of births and Total Fertility Rate}

There were 708,711 live births in England and Wales in 2008. This is an increase of 2.7 per cent on the 2007 figure of 690,013 and the seventh successive annual rise in live births since 2001. The number of live births in 2008 reached the highest level since 1972 when there were 725,440 live births.

The number of live births and the Total Fertility Rate (TFR) both fluctuated throughout the twentieth century with very sharp peaks at the end of both World Wars (Figure 1). Live births peaked at near post-war levels again in 1964, when the figure was 875,972 , but since then numbers have been lower. The lowest recorded annual number of births in the twentieth century was 569,259 in 1977. In more recent years, births reached a low of 594,634 in 2001.

The TFR is the average number of children a group of women would have if they experienced the age-specific fertility rates of the calendar year in question throughout their childbearing lifespan. The TFR provides a snapshot of the current level of fertility. It can be used to examine changes in fertility over time and compare fertility levels between different populations since it is not affected by variations in the age distribution of women. However, changes in the timing of childbearing between generations can distort the TFR, so it may not reflect the average number of children that women will have by the end of their childbearing years. For example if women are delaying their childbearing to older ages, the TFR is likely to underestimate average family size.

In 2008 the TFR for England and Wales was 1.97 children per woman, 0.05 children higher than in 2007 ( 1.92 children per woman) and consistent with the increase in the number of live births in the same period. The last time the TFR exceeded 1.97, was in 1973 when it was 2.00 children per woman. A continued gradual rise has been observed in the TFR since 2001 when the lowest ever TFR was recorded at 1.63. Since the low in 2001, the number of births has increased for two reasons; rising fertility rates and an increase in the number of women in the key childbearing ages (15 to 44) living in England and Wales (an overall rise of 2.2 per cent since 2001). A consequence of the latter is that there are more women who could potentially have a birth. In contrast, the smaller rise in births as was seen in the 1980s was due mainly to the changing age distribution of the female population rather than a rise in fertility (Figure 1).

\section{Timing of childbearing}

Between 2007 and 2008, fertility rates increased across all age groups, except for women aged under 20 . Figure 2 shows that, over the last two decades, fertility rates of women in their late thirties and forties have increased, while those of women in their twenties fell during the 1980s and 1990s but have stopped falling in recent years and started to increase. The fertility rate for women aged 30 to 34 first overtook that of women aged 25 to 29 in 2004 and has since remained the age group with the highest fertility rate, reaching 113 live births per thousand women in 2008. After a period of decline in the 1990s, the fertility rate for women aged 25 to 29 has recovered to 108 live births per thousand women in 2008, the highest rate since 1995 when it was also 108 .

The trend towards later childbearing has continued in 2008. Between 2007 and 2008, the largest percentage increase in fertility rates in any 


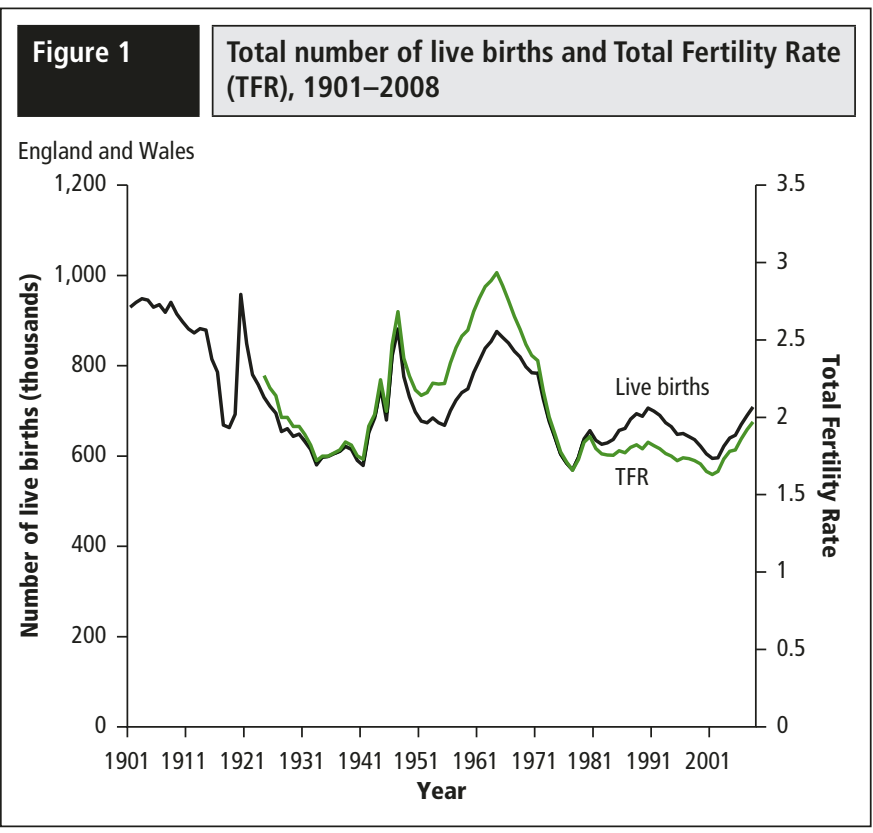

Source: FM1 2008 Tables 1.1a and 1.4

age group was observed for women aged 40 and over. Fertility rates for this age group continued a 22-year rise from 4.8 live births per thousand women in 1986 to 12.0 in 2007 and 12.6 in 2008. In contrast, women under 20 have experienced lower fertility rates compared with the previous three decades. Despite this, the fertility rate for women under 20 remained unchanged between 2007 and 2008 at 26.0 live births per thousand women.

In 2008, for all live births, the average (mean) age of mothers was 29.5 years, remaining unchanged since 2005 . Ten years previously, in 1998 , the average age was 28.9 years. The average age of women at first birth was 27.6 years in 2008 compared with 26.9 years in 1998. When standardised, to take account of the changing age structure of the female population, the mean age increased by one year over the decade from 28.3 years in 1998 to 29.3 in 2008 . The standardised mean age at first birth increased from 26.3 years in 1998 to 27.5 in 2008, (see Background

\section{Figure 2}

Age-specific fertility rates, 1938-2008

England and Wales

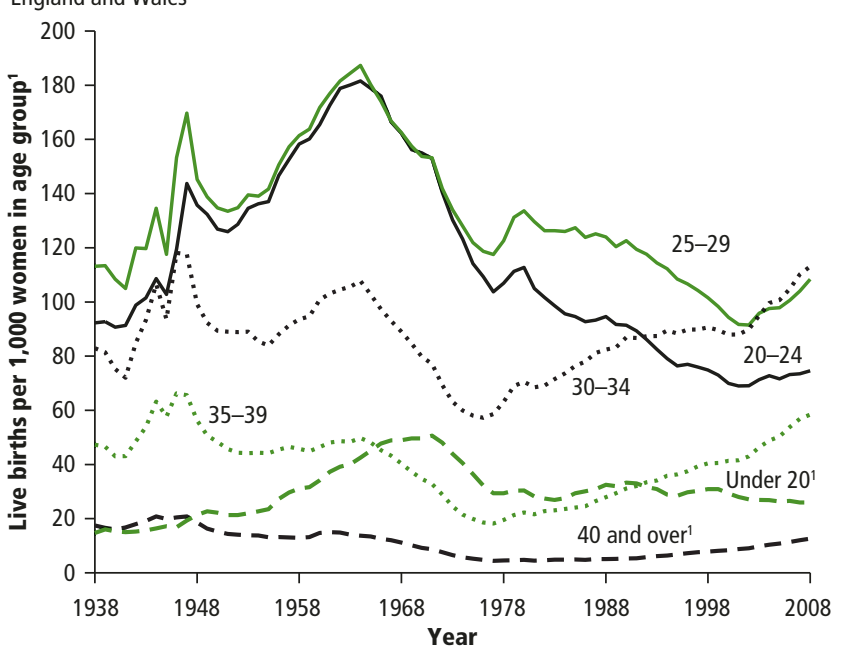

1 The rates for women aged under 20 and 40 and over are based upon the population of women aged $15-19$ and $40-44$ respectively. Source: FM1 2008 Table 3.1b

\section{Figure 3}

Estimated distribution of women aged $45^{1}$ by number of live-born children: year of birth, 1922-1963

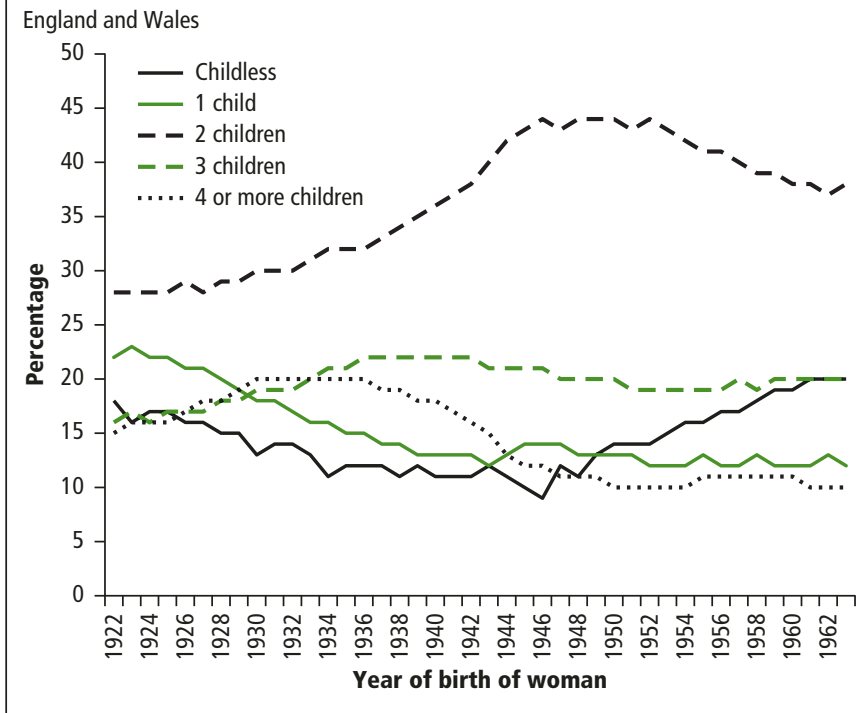

1 Includes births at ages over 45.

Source: FM1 2008 Table 10.5

Notes 2, 3 and 4). The standardised mean age of fathers at birth is generally around three years higher than the mean age of the mother ${ }^{1}$. In 1998, the standardised mean age of father was 31.5 years and it increased to 32.4 years in 2008 .

\section{Family size}

Changes in family size have a long-term impact on the population structure. Estimates of the average number of children that will be born to women contribute to projections of the future population size. An average family size of just under 2.1 children per woman is needed for the population to replace itself in the longer term if mortality rates are constant and there is no net migration. ${ }^{2}$

Trends in true birth order (see Background Note 3) show that childlessness among women aged 45 has almost doubled over the last two decades. One in five women born in 1963 (who reached age 45 in 2008) remained childless (Figure 3). This compares with just over one in nine women born around 1943 (who reached age 45 around 1988). For the most recent cohorts (women born from 1961 to 1963), the percentage of women who remained childless at age 45 was the same as the percentage of women who had three children ( 20 per cent). The last time this was observed was for the 1925 cohort, whereas women born in the 1930s, 1940s and 1950s were more likely to have three children than to be childless. Two children remains the most common family size in England and Wales with nearly four in ten ( 38 per cent) women who reached age 45 in 2008 having two children.

Average completed family size has decreased for cohorts that have most recently reached the end of their childbearing years, compared with those who finished earlier. Women born in 1963 had an average of 1.93 children per woman, while those born in 1923 and 1943 had an average of 2.10 and 2.24 children per woman respectively.

\section{Marital status}

The growing proportion of births outside marriage (Figure 4) suggests that childbearing has continued to become less strongly associated with marriage, due in part to the greater acceptability of, and rise in, cohabitation. $^{3}$ 


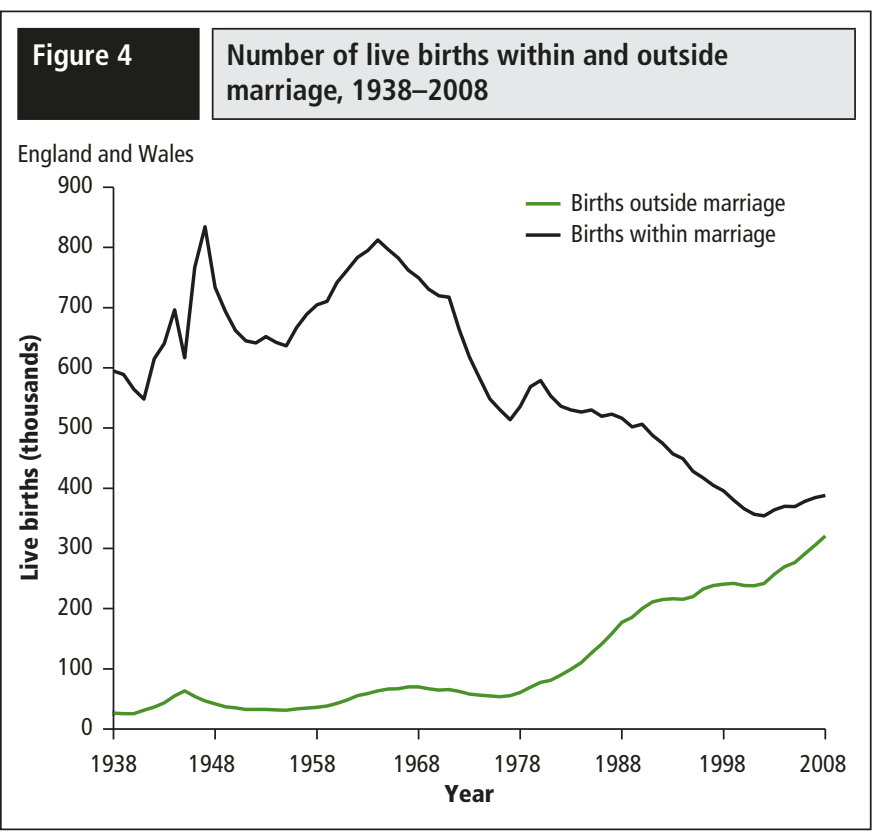

Source: FM1 2008 Table 1.1a

Between 2007 and 2008, live births outside marriage continued to increase reaching 45.3 per cent, a rise of 1.0 per cent. Figure 5 shows that the percentage of births outside marriage is higher for all age groups in 2008 than in 1998. Women under 30 have a higher percentage of births outside marriage than older women, with the highest proportions at the youngest ages. In 2008, 93.9 per cent of births to women aged under 20 occurred outside marriage compared with 35.9 per cent of births to women aged 40 and over. Over the last decade, the largest increase in the proportion of births outside marriage occurred among 20 to 24 year olds, rising from 59.7 per cent in 1998 to 71.9 per cent in 2008 . The proportion of births outside marriage to women aged 25 to 29 has also increased markedly, from 32.3 per cent in 1998 to 42.8 per cent in 2008 .

Of the births registered outside marriage in $2008,85.8$ per cent were registered jointly by parents living at either the same or different addresses, an increase of nearly one per cent since 2007 . Sole registrations represented 6.4 per cent of all births in 2008; only the mother's details are recorded on these birth registrations.

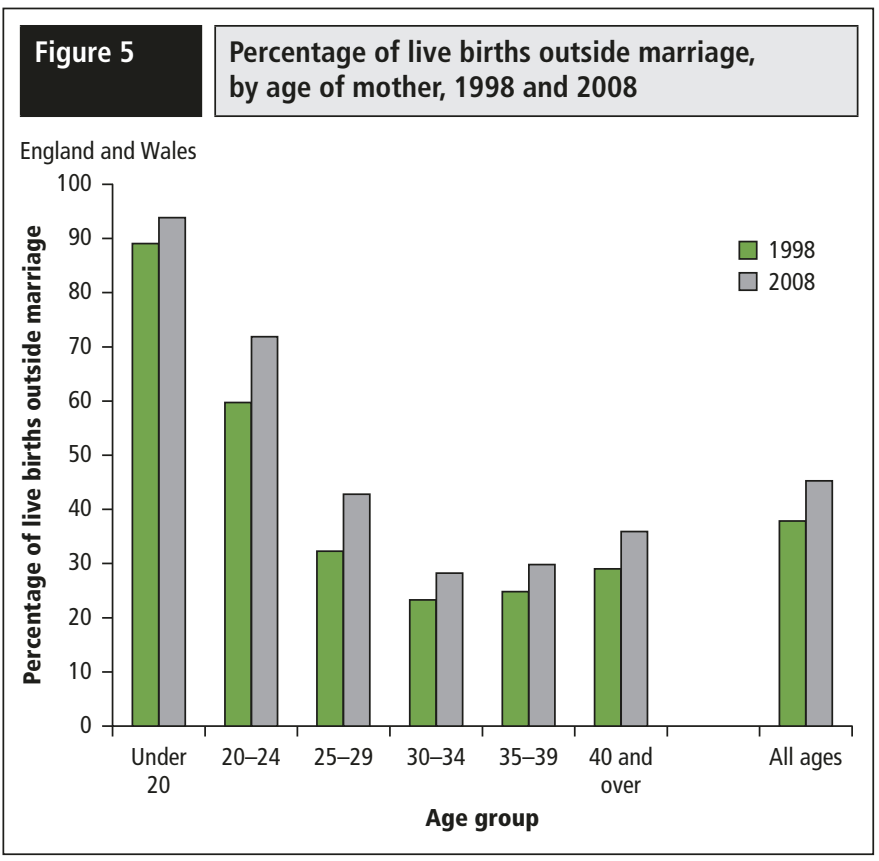

Source: FM1 2008 Table 3.1a

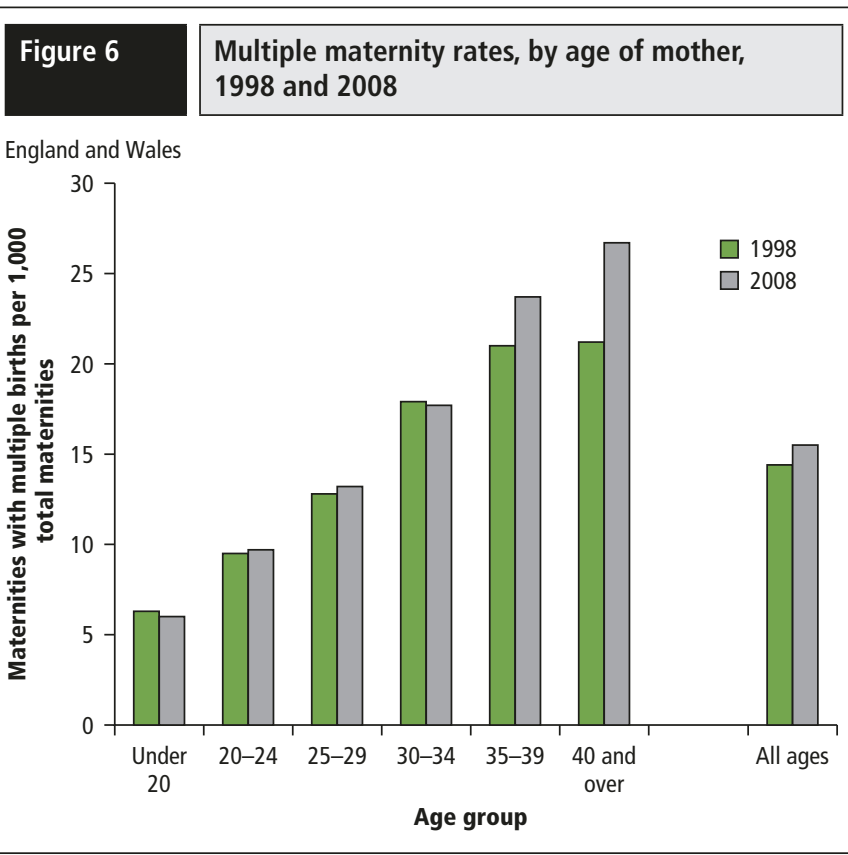

Source: FM1 2008 Table 6.1b

\section{Multiple births}

In $2008,10,679$ women gave birth to twins, 174 to triplets and one to quadruplets. These maternities include both live births and stillbirths. The multiple maternity rate increased to 15.5 maternities with multiple births per 1,000 women giving birth in 2008, compared with 15.3 in 2007. This represents an 8 per cent increase since 1998 when the multiple maternity rate was 14.4 maternities with multiple births per 1,000 women giving birth.

Figure 6 shows that women aged 40 and over experienced the highest multiple maternity rate in 2008 (26.7 per 1,000 maternities) and also the largest increase in this rate over the previous decade. In 1998, the multiple maternity rate for women aged 40 and over was similar to the rate for women aged 35 to 39 .

Married women have more multiple births than unmarried women: in 2008 the multiple maternity rate for married women was 17.9 per 1,000 maternities, compared with 12.6 for unmarried women.

\section{Fertility patterns within the United Kingdom}

The TFR for the United Kingdom paralleled the trend in England and Wales by increasing for the seventh year running to 1.96 children per woman in 2008, the highest level since 1973. Among the constituent countries in 2008, the TFR increased by between 3 and 5 per cent on the 2007 figure; Northern Ireland's TFR remained the highest of the constituent countries in 2008 (2.11 children per woman), while Scotland's fertility remained lower than the UK average (at 1.80 children per woman). The TFRs in England (1.97) and Wales (1.96) were close to the UK average.

In 2008, at least half of all live births in Scotland (50 per cent) and Wales (56 per cent) were outside marriage. Northern Ireland had the lowest proportion of births outside marriage (39 per cent), while in the United Kingdom as a whole, 45 per cent of births were outside marriage (Table 1).

Recent analysis of subnational trends in fertility between 1986 and 2006 has shown that the considerable changes in fertility at national level over this period are also evident at regional level. However, trends within individual local authorities can differ substantially from 


\begin{tabular}{|c|c|c|c|c|c|c|c|c|c|c|}
\hline \multirow[t]{2}{*}{ Area of usual residence } & \multirow{2}{*}{$\begin{array}{l}\text { Total fertility } \\
\text { rate }\end{array}$} & \multicolumn{7}{|c|}{ Age-specific fertility rates (ASFRs) ${ }^{1}$} & \multirow{2}{*}{$\begin{array}{l}\text { Percentage of births } \\
\text { outside marriage }\end{array}$} & \multirow{2}{*}{$\begin{array}{l}\text { Percentage of births to mothers } \\
\text { born outside the UK }\end{array}$} \\
\hline & & All ages & $<20$ & $20-24$ & $25-29$ & $30-34$ & $35-39$ & $40+$ & & \\
\hline United Kingdom² & 1.96 & 63.4 & 26.0 & 73.5 & 107.9 & 113.1 & 58.2 & 12.4 & 45 & 23 \\
\hline England ${ }^{2}$ & 1.97 & 63.9 & 25.7 & 74.3 & 108.1 & 113.4 & 58.9 & 12.8 & 45 & 25 \\
\hline Wales $^{2}$ & 1.96 & 61.7 & 31.2 & 80.1 & 114.4 & 106.4 & 49.8 & 9.2 & 56 & 10 \\
\hline Scotland ${ }^{3}$ & 1.80 & 57.0 & 26.7 & 66.3 & 100.9 & 102.7 & 51.3 & 10.1 & 50 & 13 \\
\hline Northern Ireland & 2.11 & 68.2 & 23.0 & 65.6 & 120.5 & 131.1 & 67.0 & 12.6 & 39 & 12 \\
\hline
\end{tabular}

1 The rates for women of all ages, under 20, and 40 and over are based upon the population of women aged 15-44, 15-19 and 40-44 respectively.

2 Figures for England and Wales separately exclude events for persons usually resident outside England and Wales (252 in 2008). These events are included in the totals for the United Kingdom.

3 The TFR for Scotland is calculated excluding records where mother's age was 'not stated' (26 in 2008). The ASFR for all ages, also known as the General Fertility Rate (GFR), is calculated including these records.

Source: Office for National Statistics (FM1 2008 Tables 7.1, 7.3 and 9.2), General Register Office for Scotland, Northern Ireland Statistics and Research Agency

the trends of the region within which they are located ${ }^{4}$. Details of live births by area of residence in England and Wales in 2008 are available in Population Trends 137.5

\section{Births to mothers born outside the United Kingdom}

There were 170,834 births in England and Wales in 2008 to mothers born outside the United Kingdom, accounting for 24 per cent of all live births in England and Wales. This is the highest proportion since the collection of the parents' country of birth at birth registration was introduced in 1969. The proportion of births to foreign-born women has increased every year since 1990 when it was just under 12 per cent, with a marked rise over the last decade: the proportion of births to mothers born outside the United Kingdom was 14 per cent in 1998 (Figure 7).

When only those births that include the father's details on the registration are considered, 25 per cent of births were to mothers born outside the United Kingdom and 18 per cent of births had both parents born outside the United Kingdom. These two proportions indicate that for around one in three births to foreign-born mothers, the child's father was born in the United Kingdom.

Figure 8 shows that over the last decade in England and Wales, women aged 25 to 29 and 30 to 34 have experienced the greatest increase in the

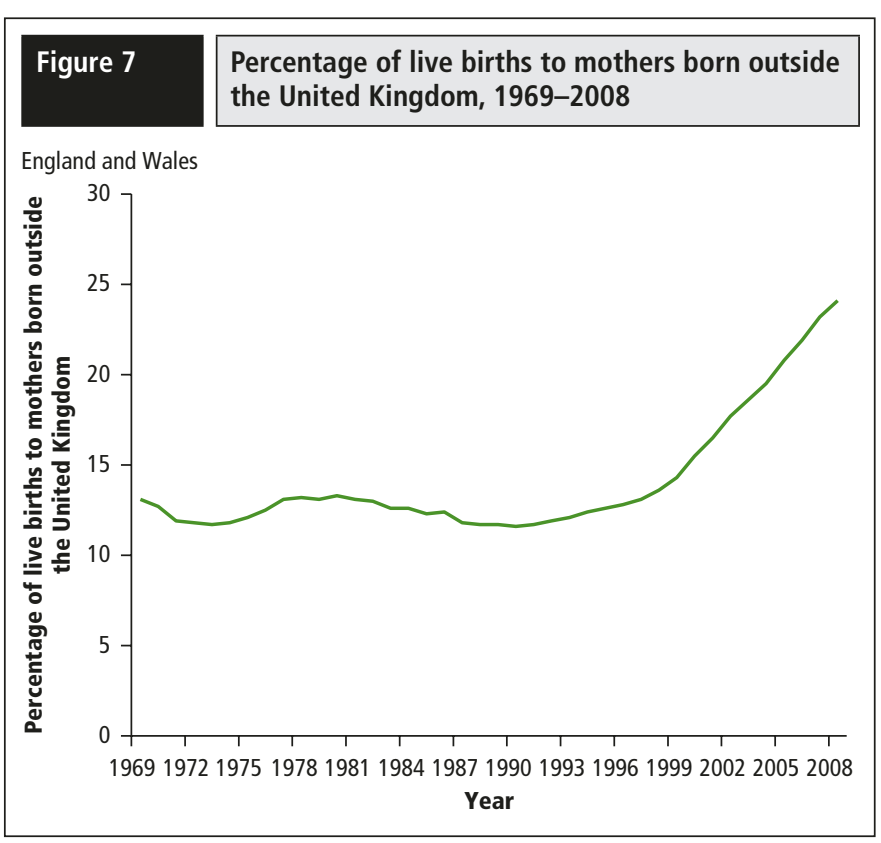

Source: FM1 2008 Table 9.1 percentage of births to mothers born outside the United Kingdom. In these age groups, the percentage of live births to non-UK born mothers has more than doubled since 1998 , rising to 28 per cent for women aged 25 to 29 and 27 per cent for women aged 30 to 34 in 2008. Births to nonUK born women in their early twenties and late thirties have also risen considerably since 1998: the percentage of live births to mothers born outside the United Kingdom increased by just under half for women aged 20 to 24 and 35 to 39 , rising to 21 per cent and 23 per cent respectively in 2008 .

The estimated TFRs (see Background Note 5) for UK born and non-UK born women living in England and Wales show that UK born fertility has risen from 1.68 children per woman in 2004 to 1.84 in 2008. In contrast, there has been little change over the past four years in the estimated TFR for women born outside the UK. ${ }^{6}$ However, higher levels of fertility continue to be observed amongst non-UK born women living in England and Wales in all age groups. In 2008, the estimated TFR for non-UK born women was 2.51. Women born outside the UK are making up an increasing share of the childbearing population in England and Wales (estimates based on the Annual Population Survey); Between 2004 and 2008, the proportion of women of childbearing age who were born outside the UK grew from 13 per cent to 16 per cent. This group has higher fertility on average than those born in the UK. Therefore, their

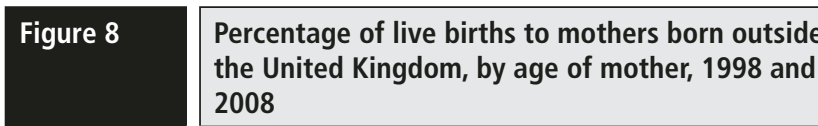

England and Wales

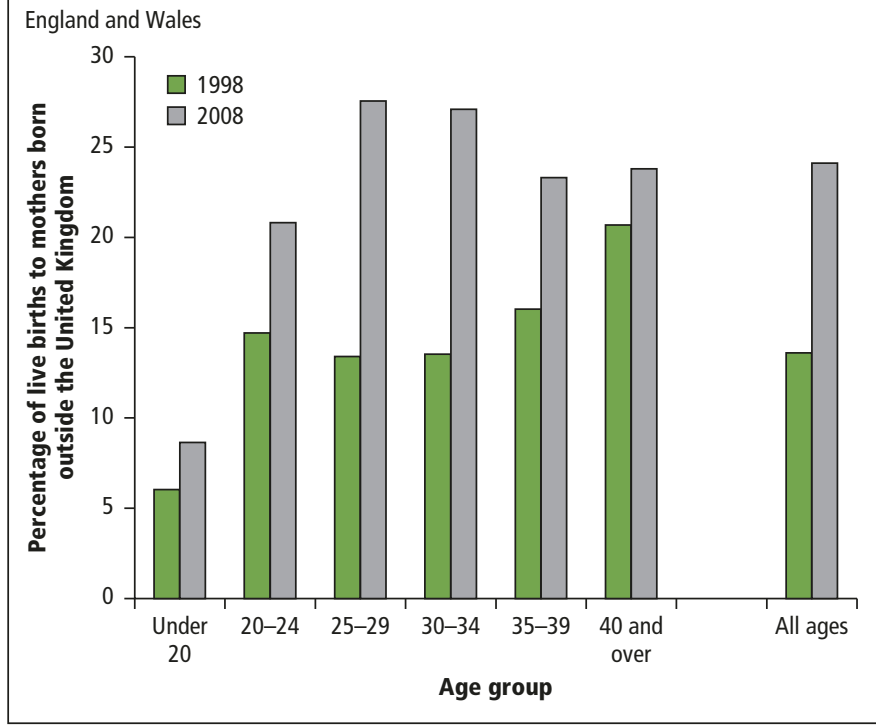

Source: FM1 2008 Table 9.4 


\section{Key findings}

- There were 708,711 live births in England and Wales in 2008, an increase of 2.7 per cent compared with 2007, and the highest annual number of births since 1972

- The TFR for England and Wales was 1.97 in 2008, a 2.6 per cent increase from 1.92 in 2007

- Women in their early thirties continued to have the highest fertility rate in 2008: 113.1 live births per thousand women

- The unstandardised average (mean) age of women giving birth in 2008 remained at 29.5 years while the average age for women at first birth was 27.6 years

- The percentage of live births outside marriage continued to rise, to 45.3 per cent of live births in 2008

- The multiple maternity rate increased slightly to 15.5 per 1,000 maternities in 2008 compared with 15.3 in 2007.

- Births to mothers born outside the United Kingdom accounted for 24 per cent of all live births in 2008. This proportion has increased every year since 1990 when it was just under 12 per cent

increasing population share is contributing to the increase in the overall TFR, even though their fertility is fairly stable.

In England and Wales in 2008, births to mothers born in the EU (excluding the UK), as constituted in 2008, represented 6.1 per cent of all live births, of which births to mothers born in one of the 12 countries that have joined the EU since 2004 represented 3.6 per cent of all live births. Mothers born in Asia contributed to 8.6 per cent of all live births and mothers born in Africa contributed 5.6 per cent

In 2008 the three most common countries of birth of mothers from outside the UK were Pakistan, Poland and India. Between 2001 and 2006, for births in England and Wales, Pakistan and India, together with Bangladesh, were consistently the three most common countries of birth for non-UK born mothers. However, Poland replaced Bangladesh as the third most common country in 2007 rising to second place in 2008. In the main, the ten most common countries have remained fairly similar across the eight year period since 2001 .

Tables and further commentary on live births by mothers' country of birth including by area of residence in England and Wales is available at: www.statistics.gov.uk/statbase/Product.asp?vlnk=14408

\section{Background Notes}

1. The population estimates used to calculate the fertility rates in this update were the most up-to-date at the time of publication. Population estimates for mid-2008 were published on 27 August 2009. More information on population estimates is available at: www.statistics.gov.uk/popest.
2. The unstandardised mean age is the average age of mothers who give birth in a particular year. Comparisons of unstandardised mean ages are affected by changes in the age structure of the population over time. The standardised mean age is a measure which allows fertility trends to be separated out from the effects of changes in the population's age structure. It is therefore more useful for comparing mean ages across population subgroups and over time.

3. At birth registration, the number of previous births is only collected for births within marriage; therefore information on birth order is not complete. The partial information on birth order from registration data is supplemented with data from the General Household Survey to give estimates of true birth order.

True birth order estimates for England and Wales were updated in 2008 to incorporate information from the General Household Survey for 2004-06. (For an explanation of how true birth order is calculated see Smallwood S $\left.(2002)^{7}\right)$.

4. The average age at first birth is based on the estimated true birth order for all births whether inside or outside marriage.

5. The estimated TFRs for UK and non-UK born women have been produced using estimated populations from the Annual Population Survey (APS) for the denominators. The APS is a combined survey of households in Great Britain, comprising the Labour Force Survey plus various sample boosts. TFRs estimated using population denominators from household surveys may differ slightly from actual published TFRs. This is because the population denominators derived from the APS are produced before the mid-year population estimates are available, so can differ slightly. The 2008 APS estimates are weighted to the 2004-based National Population Projections, as the last reweighting was completed in 2007 , but they will be reweighted to mid-2008 population estimates in early 2010 . Further information on the APS can be found in Volume 6 of the Labour Force Survey User Guide available at: www.statistics.gov.uk/statbase/Product. asp?vlnk=1537.

\section{References}

1 Office for National Statistics (2009) 'Patterns of fatherhood in England and Wales, 1964-2007' Population Trends 136, 103-107.

2 Smallwood S and Chamberlain J (2005) 'Replacement Fertility, what has it been and what does it mean?', Population Trends 119, $16-27$.

3 Chamberlain J and Gill B (2005) 'Fertility and Mortality', in Focus on People and Migration, ONS, 71-90.

4 Tromans N, Natamba E, Jefferies J and Norman, P (2008), 'Have national trends in fertility between 1986 and 2006 occurred evenly across England and Wales?', Population Trends 133, 7-19.

5 Office for National Statistics (2009) 'Live births in England and Wales 2008: area of residence', Population Trends 137, 81-88.

6 Tromans N, Natamba E and Jefferies J (2009), 'Have women born outside the UK driven the rise in UK births since 2001?', Population Trends 136, 28-42.

7 Smallwood S (2002) 'New estimates of trends in births by birth order in England and Wales', Population Trends 108, 32-48. 